\title{
INFORMATION ABOUT THE PROJECT, PROFESSIONAL PREPAREDNESS OF TEACHERS IN THE AREA OF RISK BEHAVIOUR AND ITS PREVENTION IN THE MORAVIAN-SILESIAN REGION
}

\author{
Jitka Skopalová
}

The national strategy of primary prevention of risk behaviour for the period 2013-2018 within the competence of the Ministry of Education, Youth and Sports of the Czech Republic has set the major objective of the prevention system to minimize the genesis and reduce the level of risk behaviour in children and young people. The solution to the negative consequences of risk behaviours in children and the youth has to be supported by much effort not only on the part of the parents, but especially of the teachers. The effort of teachers and educators at schools and educational facilities is to stop the occurrence of risk behaviour in students, or try to minimize it. Conditions for success here are mainly formed by educated and qualified teachers who are equipped with the appropriate knowledge, skills, abilities and competences in general to address risk behaviour.

Thus motivated, the team of academic staff of the Institute of Pedagogical and Psychological Sciences or the Faculty of Public Policies of Silesian University in Opava prepared the project Professional Preparedness of Teachers in the Area of Risk Behaviour and Its Prevention in the Moravian-Silesian Region, which was supported by the grant subsidy Support of Science and Research in the Moravian-Silesian Region 2016 the findings of which is presented in two monographs: Professional Preparedness of Teachers in the Area of Risk Behaviour and Its Prevention in the Moravian-Silesian Region I Pedagogical Aspects and Professional Preparedness of Teachers in the Area of Risk Behaviour and Its Prevention in the Moravian-Silesian Region II Psychological Aspects. The listed publications are one of the outputs of the project.

The main objective of the research investigation was to determine the possible room for improvement in the professional readiness of teachers to address specific problematic situations in relation to instruction and education outside time of teaching at primary schools. The target group of the empirical research consisted of both $1^{\text {st }}$ and $2^{\text {nd }}$ stage primary school teachers of selected schools and also the directors and school prevention methodologists of these schools. The survey sample consisted of 302 respondents: teachers from 12 different elementary schools in the Moravian-Silesian region, 12 directors and 11 school prevention methodologists of their primary schools.

In the publications which we presented to the professional public, educators and students in teacher training, we dealt with the theoretical basis which connects to the subject area. 
In the text of the monograph Pedagogical Aspects I, we deal with the theoretical starting points of the issue of risk behaviour, prevention factors at primary school and also processes to solve educational problems. The following is an interpretation of statistical data obtained from the database of the Ministry of Education, Youth and Sports of the Czech Republic which are connected to the issues under examination, and also a description of the publicly available university materials for the facilitation of current training of teachers in the area of risk behaviour and its prevention at selected faculties. The below referred relates to the research presumption that future teachers are not trained comprehensively within the framework of pedagogic competence (not only at pedagogical faculties, but also at other faculties training teachers) in the area of prevention of risk behaviour in schools and educational facilities. We consider chapter four of the submitted text as the key chapter in which we present the results of semi-structured interviews with 12 of the school directors and with 11 school prevention methodologists. The text of this chapter introduces the procedures and forms of cooperation with other bodies in addressing specific undesirable phenomena in the classroom.

The monograph Psychological Aspects of II consists of three parts. The first one is devoted to the pupil, their characteristics in the period of childhood and adolescence and to possible problem behaviour. The second part is generally focused on the teachers, their competences, social skills, authority, but also on the climate of the school and the risk of the burnout syndrome. The third part of the theoretical part is specifically focused on the class teacher, classroom relations, classroom climate, teacher-student relationships, relationships among the pupils, and teacher-parent relationships. The last part includes the results of a questionnaire survey that was performed in the year 2017 with primary school teachers.

Despite the possible "regional context", we believe that the findings may be considered as relevant or at least as inspirational for the professional, and above all the educating public. We also believe that the findings can be used for the creation of an effective Minimum Preventive Programmes at individual schools, as they will be based on the same specific knowledge and need of pupils at these schools.

The publications mentioned may be inspiration to all who will want to deal with the topic in more detail.

\section{Author}

doc. PhDr. Jitka Skopalová, Ph.D.

Faculty of Public Policies in Opava, Silesian University in Opava

Institute of Pedagogical and Psychological Sciences

Bezručovo nám. 885/14, 74601 Opava, Czech Republic

jitka.skopalova@fvp.slu.cz 